\title{
Intrapreoptic Microinjection of GHRH or Its Antagonist Alters Sleep in Rats
}

\author{
Jianyi Zhang, ${ }^{1}$ Ferenc Obál Jr, ${ }^{4}$ Tong Zheng, ${ }^{2}$ Jidong Fang, ${ }^{3}$ Ping Taishi, ${ }^{3}$ and James M. Krueger ${ }^{3}$ \\ Departments of ${ }^{1}$ Physiology and Biophysics and ${ }^{2}$ Anatomy and Neurobiology, University of Tennessee, Memphis, \\ Tennessee 38163, 3 Department of Veterinary and Comparative Anatomy, Pharmacology, and Physiology, Washington \\ State University, Pullman, Washington 99164-6520, and ${ }^{4}$ Department of Physiology, A. Szent-Györgyi Medical University, \\ Szeged, Hungary
}

Previous reports indicate that growth hormone-releasing hormone $(\mathrm{GHRH})$ is involved in sleep regulation. The site of action mediating the nonrapid eye movement sleep (NREMS)-promoting effects of $\mathrm{GHRH}$ is not known, but it is independent from the pituitary. GHRH $(0.001,0.01$, and $0.1 \mathrm{nmol} / \mathrm{kg})$ or a competitive antagonist of $\mathrm{GHRH}(0.003,0.3$, and $14 \mathrm{nmol} / \mathrm{kg})$ was microinjected into the preoptic area, and the sleep-wake activity was recorded for $23 \mathrm{hr}$ after injection in rats. GHRH elicited dosedependent increases in the duration and in the intensity of NREMS compared with that in control records after intrapreoptic injection of physiological saline. The antagonist decreased the duration and intensity of NREMS and prolonged sleep latency. Consistent alterations in rapid eye movement sleep (REMS) and in brain temperature were not found. The GHRH antagonist also attenuated the enhancements in NREMS elicited by $3 \mathrm{hr}$ of sleep deprivation. Histological verification of the injection sites showed that the majority of the effective injections were in the preoptic area and the diagonal band of Broca. The results indicate that the preoptic area mediates the sleeppromoting activity of $\mathrm{GHRH}$.

Key words: GHRH; antagonist; intrapreoptic microinjection; non-REM sleep; EEG slow-wave activity; hypothalamus
Growth hormone-releasing hormone (GHRH) is involved in the humoral regulation of sleep. Systemic injection of exogenous GHRH promotes nonrapid eye movement sleep (NREMS) in humans (Steiger et al., 1992; Kerkhofs et al., 1993; Marshall et al., 1996) and rats (Obál et al., 1996). Intracerebroventricular administration of GHRH increases NREMS and enhances slow-wave activity (SWA) in the electroencephalogram (EEG) during NREMS in rats and rabbits (Ehlers et al., 1986; Nistico et al., 1987; Obál et al., 1988). Inhibition of endogenous GHRH using either a peptide antagonist (Obál et al., 1991) or anti-GHRH antibodies (Obál et al., 1992) suppresses spontaneous sleep. Blockade of endogenous GHRH by means of immunoneutralization prevents the enhanced recovery sleep after short-term sleep deprivation (Obál et al., 1992). Furthermore, NREMS is significantly reduced in a transgenic mouse model with a deficiency in the somatotropic system (Zhang et al., 1996). Hypothalamic GHRH mRNA displays a diurnal rhythm; the highest levels occur at light onset (Bredow et al., 1996; Toppila et al., 1997), i.e., at the beginning of the rest period when the duration of NREMS and the amplitudes of EEG slow waves are the highest (Borbély, 1982; Feinberg, 1984). Hypothalamic GHRH mRNA levels increase after sleep deprivation (Toppila et al., 1997; Zhang et al., 1999). GHRH peptide content also exhibits significant diurnal variations with low concentrations in the early light period, gradual in-

\footnotetext{
Received Dec. 15, 1998; accepted Dec. 22, 1998.

This work was supported in part by National Institutes of Health Grants NS27250, NS-25378, and NS-31453 to J.M.K. and by the Hungarian National Science Foundation Grant OTKA-16080 to F.O. We thank Dr. Levente Kapás, Dr. Charles J. Wilson, and Mr. Sz. Tóth for their help with these experiments.

Correspondence should be addressed to Dr. James M. Krueger, Department of Veterinary and Comparative Anatomy, Pharmacology, and Physiology, Washington State University, College of Veterinary Medicine, 205 Wegner Hall, Pullman, WA 99164-6520.

Copyright (ㄷ) 1999 Society for Neuroscience $\quad 0270-6474 / 99 / 192187-08 \$ 05.00 / 0$
}

creases later in the light period, and decreases during the dark period. GHRH peptide is significantly depleted during sleep deprivation, and the depletion continues during the first few hours of recovery (Gardi et al., 1998).

There are two distinct pools of GHRHergic neurons in the hypothalamus; they are found in the arcuate nucleus and in extra-arcuate locations, including an area around the ventromedial nucleus and the paraventricular nucleus (Merchenthaler et al., 1984; Sawchenko et al., 1985; Daikoku et al., 1986). The control of pituitary GH secretion is the major function of the intra-arcuate GHRHergic neurons. Although the extra-arcuate GHRHergic neurons may also contribute to the regulation of GH secretion, these neurons project predominantly to structures in the basal forebrain (Sawchenko et al., 1985). The preoptic area, which also receives GHRHergic innervation, is assumed to play a fundamental role in sleep regulation (for review, see Szymusiak, 1995). It is hypothesized that stimulation of $\mathrm{GH}$ release and promotion of NREMS represent two independent outputs of hypothalamic GHRH neurons (Krueger and Obál, 1993). Hypophysectomy does not block the NREMS-promoting activity of exogenous GHRH (Obál et al., 1996), indicating that the somnogenic sites of GHRH are independent of the pituitary. The preoptic area/anterior hypothalamus and the arcuate, periventricular, and ventromedial nuclei as well as the pituitary are the sites in brain where GHRH receptors have been described (Takahashi et al., 1995). The aim of this study was to test the hypothesis that GHRH-responsive somnogenic sites are located in the preoptic area.

\section{MATERIALS AND METHODS}

Animal surgery. Male Sprague Dawley rats (300-350 gm) were anesthetized with ketamine and xylazine (87 and $13 \mathrm{mg} / \mathrm{kg}$, respectively). Stainless steel jewelry screws for EEG recording were implanted in the skull over the frontal and parietal cortices. A thermistor (model 4018; 
Omega Engineering, Stanford, CT) was placed over the parietal cortex for measuring brain temperature $\left(\mathrm{T}_{\mathrm{br}}\right)$. Two stainless steel electrodes were introduced into the dorsal neck muscles to record the electromyogram (EMG). A stainless steel double-guide cannula (model C235G-2.0; 26 gauge; Plastic One, Roanoke, VA) for microinjection was implanted into the preoptic area with one guide cannula on each side of the brain. The stereotaxic coordinates were as follows: $0.3 \mathrm{~mm}$ posterior from bregma, $1 \mathrm{~mm}$ away from the sagittal suture, and $7.7 \mathrm{~mm}$ in depth (Paxinos and Watson, 1986). A dummy cannula was used to seal the bottom tip of the guide cannula. Insulated leads from the screws, EMG electrodes, and thermistor were routed to a miniature plug and attached to the skull with dental cement.

The animals were housed in individual Plexiglas cages placed in environmental chambers (Hotpack 352600, Philadelphia, PA). The ambient temperature was regulated at $24 \pm 1^{\circ} \mathrm{C}$, and a $12: 12 \mathrm{hr}$ light/dark cycle was maintained throughout the $10 \mathrm{~d}$ recovery period and the entire experiment. Food and water were available ad libitum. Rats were connected to flexible recording cables at least $3 \mathrm{~d}$ before recording. Animals were handled daily around dark onset, at the time when the subsequent microinjections of GHRH were performed, or around light onset, at the time when microinjections of the GHRH antagonist were performed.

Experimental protocol. GHRH and the antagonist were injected unilaterally. Thus, each rat was tested twice with the peptides injected into the left and on another day into the right preoptic area. Each testing was preceded or followed by a control day when physiological saline was injected. The sequence of physiological saline and ipsilateral peptide injections was randomized, and there was at least $1 \mathrm{~d}$ off between two consecutive injections. The same rat received the same dose of peptide on both occasions. In addition to the recordings of sleep-wake activity after intrapreoptic injection of the peptides and physiological saline, a baseline day recording was also obtained for each treatment when no injections were performed. Comparisons between the baseline records and the records obtained after intrapreoptic administration of physiological saline aimed to determine the effects on sleep of the injection procedure itself. For the microinjection, an internal cannula $(0.1 \mathrm{~mm}$ in interior diameter) was inserted into the guide tube. The internal cannula protruded $0.5 \mathrm{~mm}$ from the bottom tip of the guide cannula. The injected volume was $0.3-0.5 \mu \mathrm{l}$ and was delivered in $1 \mathrm{~min}$. The cannula was left in place for another minute after injection. The peptides were dissolved in physiological saline.

Rats sleep relatively little at night; therefore recording during the dark period was used to detect the sleep-promoting activity of GHRH. Rat GHRH (Peninsula Laboratories, Belmont, CA) was injected in three doses $(0.001,0.01$, and $0.1 \mathrm{nmol} / \mathrm{kg}$; the sample sizes provided in Statistical analysis) at the onset of the dark period. In contrast, the long sleep durations characteristic of rats during the day provided the baseline to demonstrate sleep inhibition by the GHRH antagonist. The GHRH antagonist [ $\left(N-\mathrm{Ac}_{-} \mathrm{Tyr}^{1}, \mathrm{D}-\mathrm{Arg}^{2}\right)-\mathrm{GRF}(1-29)-\mathrm{NH}_{2}$; Bachem Laboratories, Belmont, CA] was administered in three doses $(0.003,0.3$, and 14 $\mathrm{nmol} / \mathrm{kg}$ ) just before light onset.

The effects of intrapreoptic microinjection of GHRH antagonist were also tested on the recovery sleep after sleep deprivation. The rats were sleep deprived by "gentle handling" for $3 \mathrm{hr}$ at the beginning of the light period. During deprivation, the rats stayed in their recording cage, and they were aroused by knocking or by touching them whenever they attempted to fall asleep. GHRH antagonist $(0.3 \mathrm{nmol} / \mathrm{kg})$ or physiological saline was intrapreoptically administered at the termination of sleep deprivation. The EEG, EMG, and $\mathrm{T}_{\mathrm{br}}$ were recorded for $23 \mathrm{hr}$ starting with light onset under four conditions: (1) on a baseline day without sleep deprivation and microinjection, (2) on a sleep deprivation day without microinjections, (3) on a control day with intrapreoptic microinjection of physiological saline after sleep deprivation, and (4) on an experimental day with administration of GHRH antagonist after sleep deprivation. There was at least $1 \mathrm{~d}$ off after each day of sleep deprivation.

Sleep recording and data processing. After amplification, the EEG (filtering, below 0.1 and above $40 \mathrm{~Hz}$ ) and EMG signals were digitized (128 Hz sampling rate), collected by means of computers, and saved on compact disks. $\mathrm{T}_{\mathrm{br}}$ values were sampled at $10 \mathrm{sec}$ intervals. For spectral analysis of the EEG, on-line fast Fourier transformations of the EEG signals were performed for $2 \mathrm{sec}$ intervals and averaged for $10 \mathrm{sec}$ intervals. Power density values were calculated for $0.5 \mathrm{~Hz}$ bins.

The EEG and EMG signals and the power density spectra of the EEG were displayed on the computer screen and evaluated in $10 \mathrm{sec}$ epochs to determine the states of vigilance. Wakefulness was identified by lowamplitude, fast EEG activity, intense muscle activity, and a gradual increase in $T_{b r}$ after arousal. NREMS was associated with high-voltage low-frequency EEG activity, low-amplitude EMG, and declining $\mathrm{T}_{\mathrm{br}}$ on entry. REMS was characterized by low-amplitude EEG with highly regular theta activity, a dramatic suppression in EMG with occasional muscle twitches, and a rapid rise in $\mathrm{T}_{\mathrm{br}}$ at onset. The percentage of time spent in each state of vigilance was calculated for $1 \mathrm{hr}$ periods. The results of the spectral analysis were sorted by a computer program with respect to the state of vigilance. The epochs containing movement artifacts were excluded from analyses. The power in the $0.5-4 \mathrm{~Hz}$ frequency band was integrated and used to characterize SWA, a measure of sleep intensity, during NREMS in each hour of recording.

Histological verification of microinjection sites. After termination of the experiments, Chicago sky blue ( $2 \%$ in $0.03 \mu \mathrm{l})$ was microinjected through the intrapreoptic cannula. Then the rats were anesthetized with ketamine and xylazine and perfused intracardially with isotonic saline, followed by cold $\left(4^{\circ} \mathrm{C}\right) 4 \%$ paraformaldehyde fixative, $\mathrm{pH}$ 7.4. The brains were blocked and cut with a vibratome. Coronal sections $(50 \mu \mathrm{m})$ were stained with neutral red. The histological evaluation was performed with light microscopy. Data analysis was only applied to those rats in which the injection sites were located inside the preoptic area or the diagonal band of Broca. Out of a total of 114 microinjections, the number of cannula misplacements was as follows: 1 in the experiments with GHRH at 0.01 $\mathrm{nmol} / \mathrm{kg}, 3$ and 4 in the experiments with GHRH antagonist at 0.3 and $14 \mathrm{nmol} / \mathrm{kg}$, respectively, and 2 in the sleep deprivation experiments. In addition, GHRH $(0.1 \mathrm{nmol} / \mathrm{kg})$ was deliberately microinjected in sites dorsal to the preoptic region in eight rats. The aim of these control injections was to determine whether GHRH could reach the penetrated cerebral ventricle via an upward diff usion along the shaft of the cannula (Johnson and Epstein, 1975).

Statistical analysis. In addition to misplacements of the cannula, technical failures caused some records to be lost (one in the experiments with GHRH at 0.001 and $0.1 \mathrm{nmol} / \mathrm{kg}$, one in the experiments with GHRH antagonist at $0.3 \mathrm{nmol} / \mathrm{kg}$, and four in the sleep deprivation experiments). Thus, the final sample sizes were as follows: for GHRH at 0.001 $\mathrm{nmol} / \mathrm{kg}, n=15$ in 8 rats; for GHRH at $0.01 \mathrm{nmol} / \mathrm{kg}, n=17$ in 11 rats (4 rats were injected only unilaterally); for GHRH at $0.1 \mathrm{nmol} / \mathrm{kg}, n=15$ in 8 rats; for GHRH antagonist at $0.003 \mathrm{nmol} / \mathrm{kg}, n=14$ in 7 rats; for GHRH antagonist at $0.3 \mathrm{nmol} / \mathrm{kg}, n=12$ in 8 rats; for GHRH antagonist at $14 \mathrm{nmol} / \mathrm{kg}, n=14$ in 9 rats; and for the sleep deprivation experiment, $n=10$ in 8 rats. For the statistical analysis, data obtained after microinjections into the left and the right preoptic regions were treated as independent samples because separate baseline and control records were collected for each peptide administration and identical cannula locations in both the left and right preoptic area could hardly be achieved even for the same rat. Because of malfunction of a few thermistors, the sample size for the $\mathrm{T}_{\mathrm{br}}$ results is two or three numbers less than the sample size for sleep analyses for some groups. Two-way ANOVA for repeated measures was used to compare the duration of sleep states (NREMS and REMS), SWA during NREMS, and $\mathrm{T}_{\mathrm{br}}$ between the recording days in the first $12 \mathrm{hr}$ recording period. The treatment and the time were the two factors of the ANOVA. Only treatment effects are discussed herein; it is well known that the duration of sleep states, SWA, and $\mathrm{T}_{\mathrm{br}}$ vary during the day. When appropriate, post hoc multiple comparisons were done by Student-Newman-Keuls test. Paired $t$ tests were used to analyze the latency of NREMS onset after the injections. An $\alpha$ level of $p<0.05$ was considered statistically significant.

\section{RESULTS}

\section{Intrapreoptic microinjection of physiological saline at dark and light onset}

Normal circadian variations of sleep-wake activity and $\mathrm{T}_{\mathrm{br}}$ were observed on the baseline day and after physiological saline injection in all groups of rats (Fig. 1). Thus more NREMS and REMS occurred during the day than during the night. EEG SWA had a similar pattern. In contrast, $\mathrm{T}_{\mathrm{br}}$ was relatively high at night and low during the day. Intrapreoptic injection of physiological saline at dark onset was followed by significant increases in NREMS $\left[F_{(1,46)}=23.80 ; p<0.0001\right]$, SWA $\left[F_{(1,46)}=29.63 ; p<0.0001\right]$, and REMS $\left[F_{(1,46)}=12.07 ; p<0.005\right]$ during the $12 \mathrm{hr}$ dark period. These changes varied with time (treatment $\times$ time interactions) and occurred mostly in the first $3 \mathrm{hr}$ after injection. $\mathrm{T}_{\mathrm{br}}$ rose persistently throughout the night $\left[F_{(1,41)}=102.95 ; p<\right.$ 
Dark onset injection Light onset injection

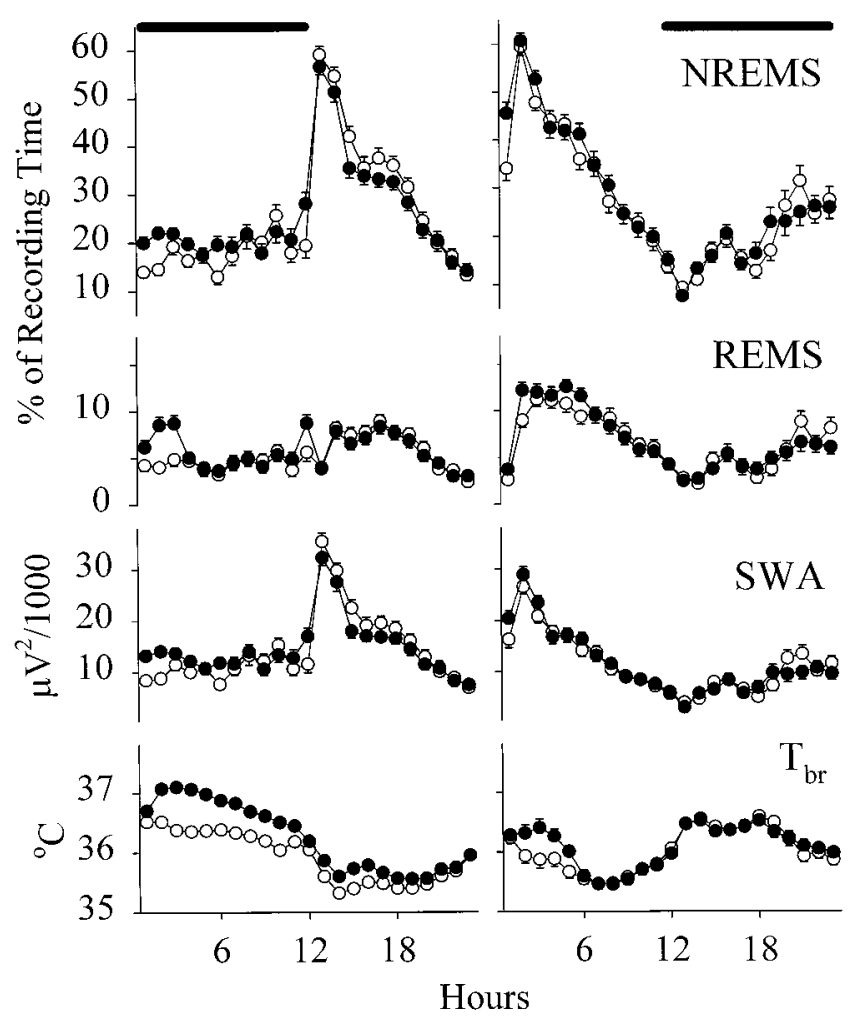

Figure 1. Mean hourly values of NREMS, REMS, EEG SWA during $N R E M S$, and $T_{b r}$ in rats on the baseline day (open circles) and on the day the rats were microinjected with physiological saline (solid circles) at dark and light onset. Means \pm SE determined for $1 \mathrm{hr}$ periods are shown for 47 and 40 trials in rats microinjected with physiological saline at dark and at light onset, respectively. The solid horizontal bars at the top indicate the dark period.

0.0001]. Also, significant increases in the duration of NREMS $\left[F_{(1,39)}=7.68 ; p<0.01\right]$, SWA $\left[F_{(1,39)}=6.15 ; p<0.02\right]$, and $\mathrm{T}_{\mathrm{br}}$ $\left[F_{(1,35)}=5.23 ; p<0.03\right]$ were observed after intrapreoptic microinjection of physiological saline at light onset. These changes subsided in a few hours (significant treatment $\times$ time interactions). REMS was not significantly altered during the light period.

\section{Effects of intrapreoptic microinjection of GHRH at dark onset}

The effects of peptide on sleep and $T_{b r}$ were evaluated with respect to control records obtained after injection of physiological saline. The GHRH- and the GHRH antagonist-induced sleep alterations were always over by the end of the first $12 \mathrm{hr}$ of recording. Therefore, the data presented are only from the first 12 hr after injection.

Compared with physiological saline, GHRH elicited dosedependent enhancements in the duration of NREMS during the $12 \mathrm{hr}$ dark period $\left[F_{(2,528)}=27.7 ; p<0.0001\right]$ (Fig. 2). The small dose of GHRH failed to alter NREMS. Significant increases in the duration of NREMS were observed in rats treated with either $0.01 \mathrm{nmol} / \mathrm{kg}\left[F_{(1,16)}=8.81 ; p<0.01\right]$ or $0.1 \mathrm{nmol} / \mathrm{kg}\left[F_{(1,14)}=\right.$ 11.23; $p<0.01]$. The duration of NREMS after GHRH at both 0.01 and $0.1 \mathrm{nmol} / \mathrm{kg}$ differed from NREMS after the small dose (Student-Newman-Keuls test, $p<0.05$ ), whereas significant differences were not found between NREMS after the two higher doses. NREMS was already enhanced in hour 1 after injection,

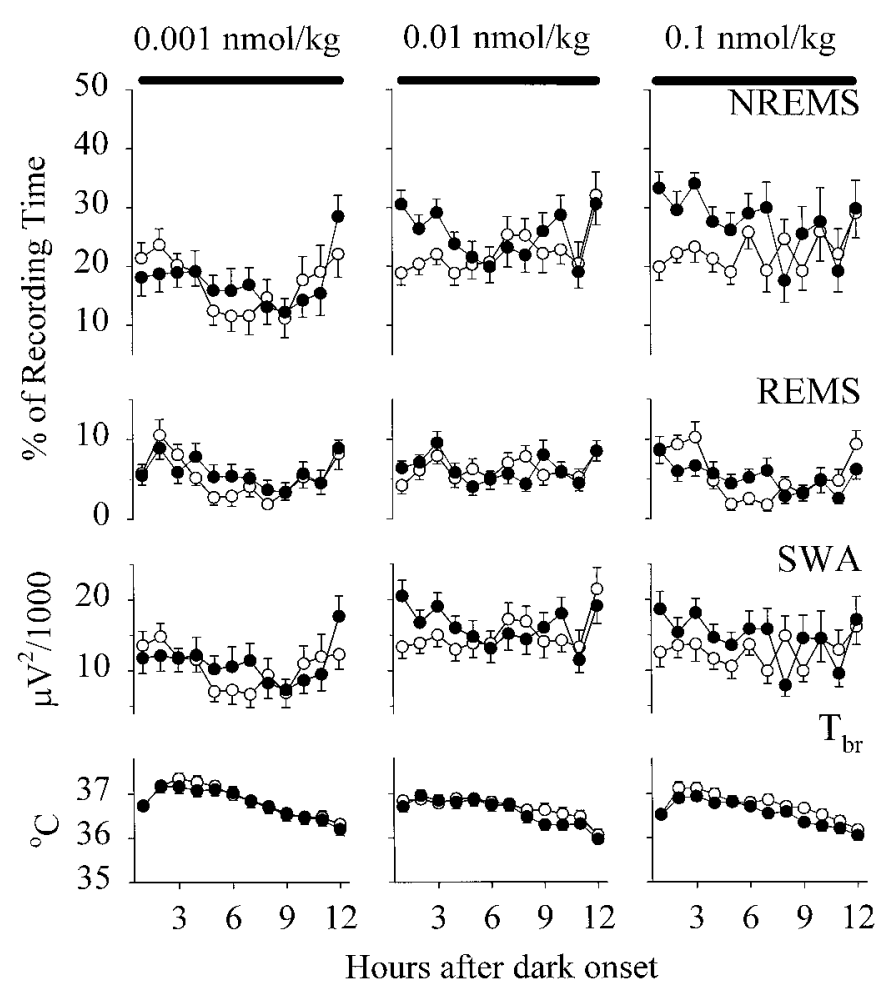

Figure 2. Mean hourly values of NREMS, REMS, EEG SWA during $N R E M S$, and $T_{b r}$ in rats microinjected with physiological saline (open circles) and with GHRH (solid circles) at doses of 0.001, 0.01, and 0.1 $\mathrm{nmol} / \mathrm{kg}$ at dark onset. Means $\pm \mathrm{SE}$ determined for $1 \mathrm{hr}$ periods are shown for 15,17 , and 15 trials in rats microinjected with GHRH at doses of $0.001,0.01$, and $0.1 \mathrm{nmol} / \mathrm{kg}$, respectively. The solid horizontal bars at the top indicate the dark period.

and the promotion of NREMS persisted for 3-4 hr after GHRH at $0.01 \mathrm{nmol} / \mathrm{kg}$, resulting in a significant treatment $\times$ time interaction $\left[F_{(11,176)}=1.97 ; p<0.05\right]$. The high dose of GHRH enhanced NREMS for 7-8 hr. The latency to the first $30 \mathrm{sec}$ NREMS episode decreased significantly in response to GHRH at $0.01 \mathrm{nmol} / \mathrm{kg}$ (control vs experimental, $23.5 \pm 6.04$ and $13.6 \pm$ $2.63 \mathrm{~min}$ ). Sleep onset after the high dose was not altered, but the control sleep latency was already relatively short in these animals (control vs experimental, $14.6 \pm 3.81$ and $13.2 \pm 2.57 \mathrm{~min}$ ). Microinjection of GHRH failed to influence REMS.

SWA responses to GHRH paralleled the changes in the duration of NREMS. Thus, SWA was not significantly affected in the group treated with GHRH at $0.001 \mathrm{nmol} / \mathrm{kg}$. In contrast, SWA was enhanced significantly after both $0.01 \mathrm{nmol} / \mathrm{kg}\left[F_{(1,16)}=5.13\right.$; $p<0.05]$ and $0.1 \mathrm{nmol} / \mathrm{kg}\left[F_{(1,14)}=7.02 ; p<0.05\right]$. The changes in SWA in response to GHRH at $0.01 \mathrm{nmol} / \mathrm{kg}$ varied with time [treatment $\times$ time interaction, $F_{(11,176)}=1.95 ; p<0.05$ ]; increments in SWA vanished after 3-4 hr. Slight but persistent increments in SWA were observed after the high dose of GHRH for $6-7 \mathrm{hr}$.

$\mathrm{T}_{\mathrm{br}}$ in animals injected with $\mathrm{GHRH}$ at either 0.001 or 0.01 $\mathrm{nmol} / \mathrm{kg}$ was not altered. Significant although slight $\left(0.2-0.3^{\circ} \mathrm{C}\right)$ decreases in $\mathrm{T}_{\mathrm{br}}$ were observed in the rats treated with $\mathrm{GHRH}$ at $0.1 \mathrm{nmol} / \mathrm{kg}\left[F_{(1,11)}=14.59 ; p<0.005\right]$.

\section{Effects of intrapreoptic microinjection of the GHRH antagonist at light onset}

NREMS was significantly suppressed after the administration of the GHRH antagonist at both $0.3 \mathrm{nmol} / \mathrm{kg}\left[F_{(1,11)}=9.49 ; p<\right.$ 


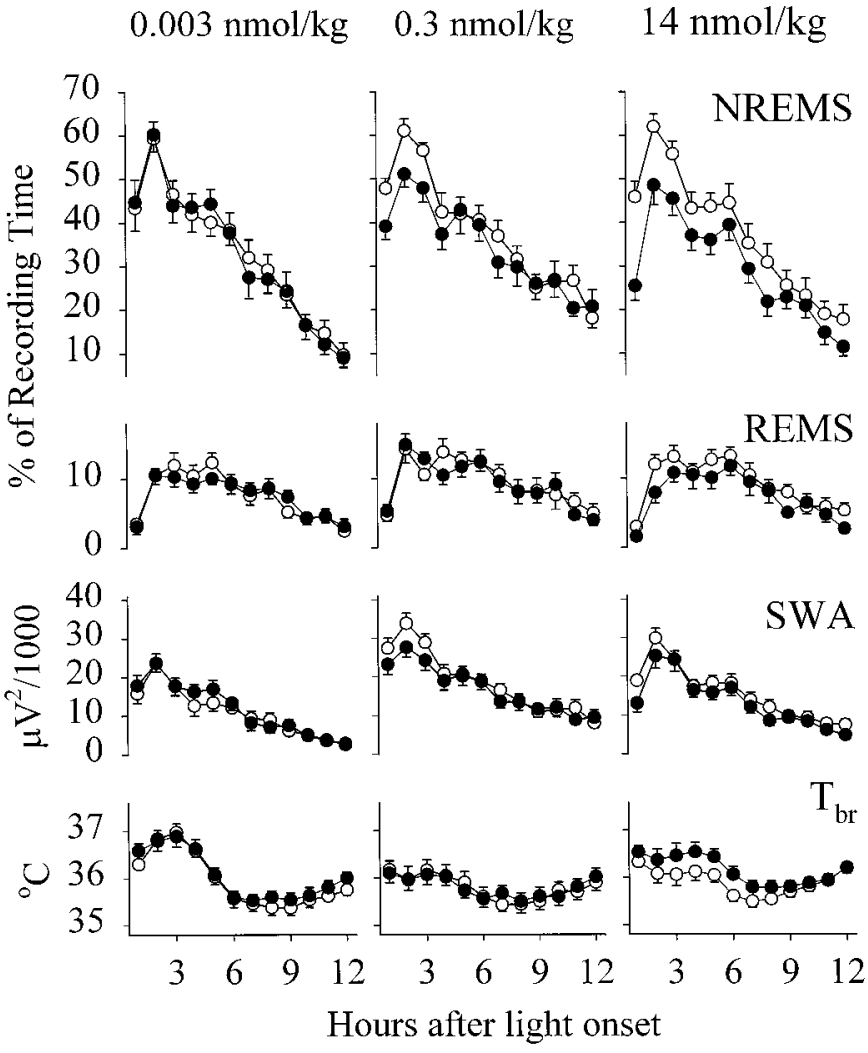

Figure 3. Mean hourly values of NREMS, REMS, EEG SWA during $N R E M S$, and $T_{b r}$ in rats microinjected with physiological saline (open circles) and with the GHRH antagonist (solid circles) at doses of 0.003, 0.3, and $14 \mathrm{nmol} / \mathrm{kg}$ at light onset. Means $\pm \mathrm{SE}$ determined for $1 \mathrm{hr}$ periods are shown for 14, 12, and 14 trials in rats microinjected with the GHRH antagonist at doses of $0.003,0.3$, and $14 \mathrm{nmol} / \mathrm{kg}$, respectively.

$0.05]$ and $14 \mathrm{nmol} / \mathrm{kg}\left[F_{(1,13)}=27.12 ; p<0.0005\right]$, whereas the GHRH antagonist at $0.003 \mathrm{nmol} / \mathrm{kg}$ did not alter NREMS (Fig. 3 ). The decrease in NREMS after the $14 \mathrm{nmol} / \mathrm{kg}$ dose of the GHRH antagonist varied with time $\left[F_{(11,143)}=2.00 ; p<0.05\right]$ and persisted for $8-9 \mathrm{hr}$. The changes in NREMS depended on the dose $\left[F_{(2,444)}=6.46 ; p<0.005\right]$. Calculated for the $12 \mathrm{hr}$ light period, NREMS after the GHRH antagonist at a dose of 14 $\mathrm{nmol} / \mathrm{kg}$ was significantly less than that after the 0.3 or 0.003 $\mathrm{nmol} / \mathrm{kg}$ doses (Student-Newman-Keuls test, $p<0.05$ ), but NREMS did not differ between the rats injected with the two lower doses of the antagonist. The latency to the first $30 \mathrm{sec}$ NREMS epoch was significantly delayed after the GHRH antagonist at $14 \mathrm{nmol} / \mathrm{kg}$ (control vs experimental, $14.8 \pm 2.57 \mathrm{vs}$ $30.3 \pm 2.61 \mathrm{~min})$. The onset of NREMS tended to increase after the GHRH antagonist at $0.3 \mathrm{nmol} / \mathrm{kg}$ (control vs experimental, $17.0 \pm 1.71$ vs $20.9 \pm 2.03 \mathrm{~min}$ ), but the difference did not reach the level of statistical significance. Sleep latency was not altered in response to the GHRH antagonist at $0.003 \mathrm{nmol} / \mathrm{kg}$ (control vs experimental, $17.4 \pm 3.50$ vs $17.2 \pm 2.49 \mathrm{~min}$ ). Slight but significant decreases in REMS were observed in the rats that received the GHRH antagonist at $14 \mathrm{nmol} / \mathrm{kg}\left[F_{(1,13)}=7.99 ; p<0.05\right]$. REMS was not altered after the two lower doses of the GHRH antagonist.

The GHRH antagonist elicited significant decreases in SWA in doses of $0.3 \mathrm{nmol} / \mathrm{kg}\left[F_{(1,11)}=11.26 ; p<0.01\right]$ and $14 \mathrm{nmol} / \mathrm{kg}$ $\left[F_{(1,13)}=12.99 ; p<0.005\right]$ for the $12 \mathrm{hr}$ light period. These changes were generally small.

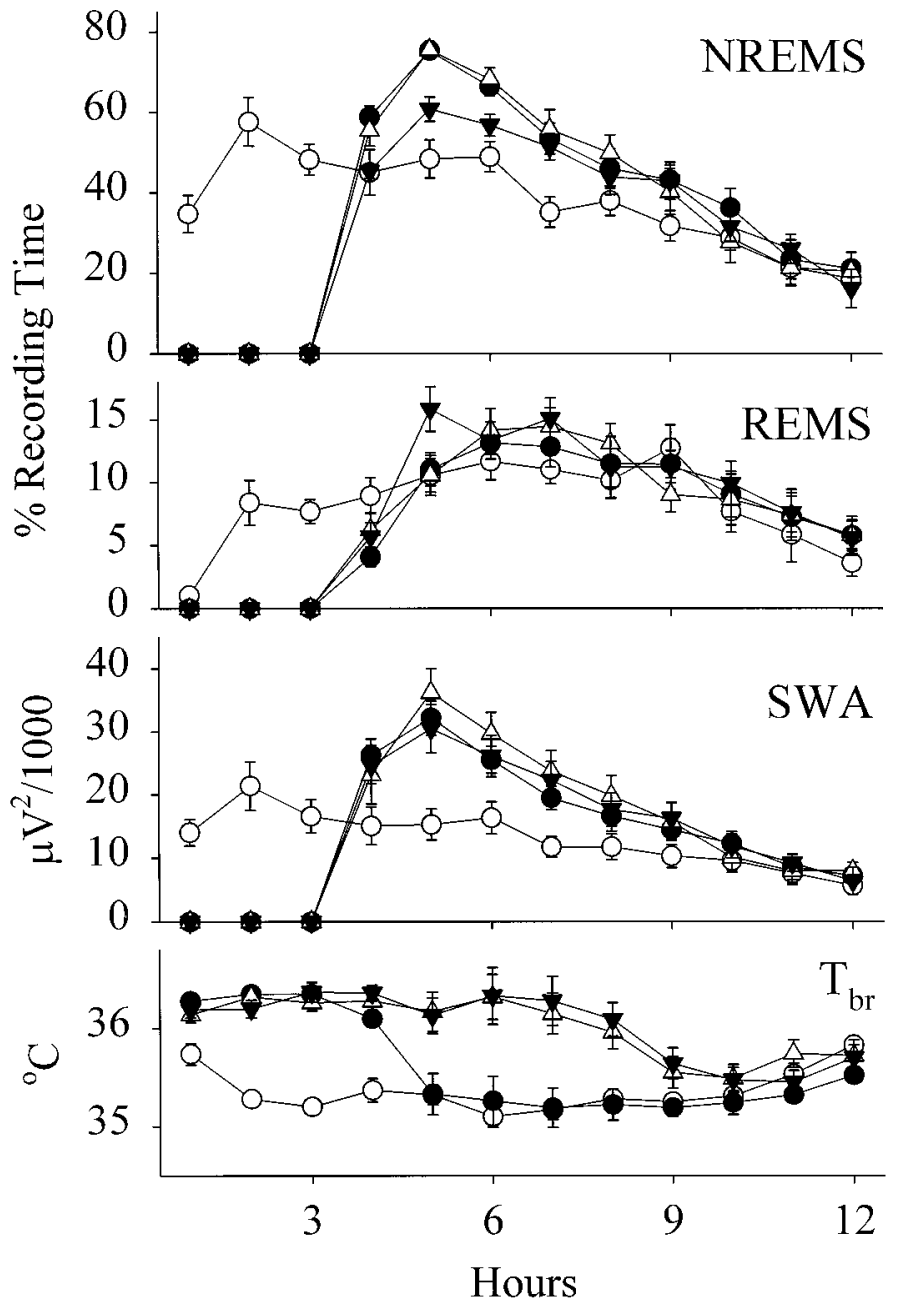

Figure 4. Mean hourly values of NREMS, REMS, EEG SWA during NREMS, and $T_{b r}$ in rats on a baseline day (open circles), on the day of 3 $\mathrm{hr}$ of sleep deprivation starting at light onset (closed circles), on the day rats were microinjected with physiological saline at the termination of $3 \mathrm{hr}$ of sleep deprivation (open triangles), and on the day rats were microinjected with the GHRH antagonist at a dose of $0.3 \mathrm{nmol} / \mathrm{kg}$ at the termination of $3 \mathrm{hr}$ of sleep deprivation (closed inverted triangles). Means \pm SE determined for $1 \mathrm{hr}$ periods are shown for 10 trials.

Compared with $\mathrm{T}_{\mathrm{br}}$ in the control records after intrapreoptic injection of physiological saline, $\mathrm{T}_{\mathrm{br}}$ in the animals treated with the GHRH antagonist at either 0.003 or $0.3 \mathrm{nmol} / \mathrm{kg}$ did not change significantly. $T_{b r}$ tended to increase after the GHRH antagonist at $14 \mathrm{nmol} / \mathrm{kg}$, but the changes did not reach the level of statistical significance.

\section{Effects of intrapreoptic microinjection of the GHRH antagonist after sleep deprivation}

Sleep deprivation for $3 \mathrm{hr}$ was followed by large increases in the duration of NREMS (Fig. 4). The NREMS enhancements peaked in hour 2 after deprivation, but slight increases persisted until hour 10 of the light period. Intrapreoptic injection of physiological saline did not alter the deprivation-induced rebound in NREMS. In contrast, the enhancements in NREMS were significantly attenuated after the administration of the GHRH antagonist at $0.3 \mathrm{nmol} / \mathrm{kg}$. Comparisons of NREMS during hours 4-12 of the light period indicated significant differences among the $4 \mathrm{~d}$ of recording $\left[F_{(3,27)}=19.40 ; p<0.0001\right]$; the differences, of 
course, depended on the time of the day [treatment $\times$ time interaction, $\left.F_{(24,216)}=1.99 ; p<0.01\right]$. NREMS on the day the GHRH antagonist was administrated after sleep deprivation differed from NREMS on all other days (Student-Newman-Keuls test, $p<0.05)$. REMS did not change after $3 \mathrm{hr}$ of sleep deprivation. There were significant variations in SWA among the $4 \mathrm{~d}$ of recording $\left[F_{(3,27)}=18.04 ; p<0.0001\right]$, but these differences resulted from the sleep deprivation-induced enhancement in SWA that was not altered by the GHRH antagonist at 0.3 $\mathrm{nmol} / \mathrm{kg}$.

$\mathrm{T}_{\mathrm{br}}$ during hours 1-12 also significantly differed among the days $\left[F_{(3,27)}=26.79 ; p<0.0001\right] . \mathrm{T}_{\mathrm{br}}$ rose significantly during sleep deprivation and returned to baseline in hour 2 after deprivation (Student-Newman-Keuls test, $p<0.05$ ). After injection of physiological saline, $\mathrm{T}_{\mathrm{br}}$ stayed high for an additional $4 \mathrm{hr}$ (StudentNewman-Keuls test, $p<0.05$ ). Compared with the effects of physiological saline, administration of the GHRH antagonist did not change the course of $\mathrm{T}_{\mathrm{br}}$.

\section{Injection sites mapping}

Figure 5 depicts the locations of the injection sites for GHRH at 0.01 and $0.1 \mathrm{nmol} / \mathrm{kg}$, for the GHRH antagonist at 0.3 and 14 $\mathrm{nmol} / \mathrm{kg}$, for the sleep deprivation experiments, and for the 18 misplaced injections. The positive (Fig. 5, closed symbols) and negative (open symbols) injection sites indicate at least $8 \%$ (percent recording time) increases or decreases in NREMS in the first $2 \mathrm{hr}$ after injection, after GHRH and the GHRH antagonist, respectively. The majority of the injections were inside of a 1 $\mathrm{mm}^{3}$ area involving the medial and lateral preoptic area and the diagonal band of Broca. Although some of the microinjections outside of this area were also effective, these were not included in the statistical analyses (Fig. 5, closed circles). Three of the misplaced and effective microinjections were in the anterior commissure, thereby suggesting that the injected solutions might have reached the preoptic area. In one case, the injection was in the immediate vicinity of the ventricle, which indicates a possible diffusion of GHRH into the CSF. In contrast, increases in NREMS were not observed after seven microinjections dorsal to the preoptic area. Also, the GHRH antagonist was not effective in six cases when injected into the anterior commissure and in one case when administered lateral to the diagonal band of Broca.

\section{DISCUSSION}

The experiments were designed to determine whether GHRH injected in a circumscribed area of the rat brain, the preoptic region, enhances sleep. Intrapreoptic injection of GHRH increased the duration of NREMS. The NREMS-promoting effect of GHRH was significantly stronger than were the changes elicited by the same volume of physiological saline. SWA, the parameter characterizing the intensity of NREMS, also was enhanced. These changes in NREMS correspond to those found after intracerebroventricular administration of GHRH in rats and rabbits (Ehlers et al., 1986; Nistico et al., 1987; Obál et al., 1988). The duration of the NREMS responses was, however, longer after intrapreoptic than after intracerebroventricular injections. NREMS was enhanced for several hours in the current experiments, whereas the NREMS-promoting activity declined $1 \mathrm{hr}$ after intracerebroventricular administration of the same doses of GHRH in rats (Obál et al., 1988). Inhibition of endogenous GHRH by means of a competitive antagonist suppressed NREMS. The same dose of the antagonist also inhibited NREMS when injected into the cerebral ventricle (Obál et al.,

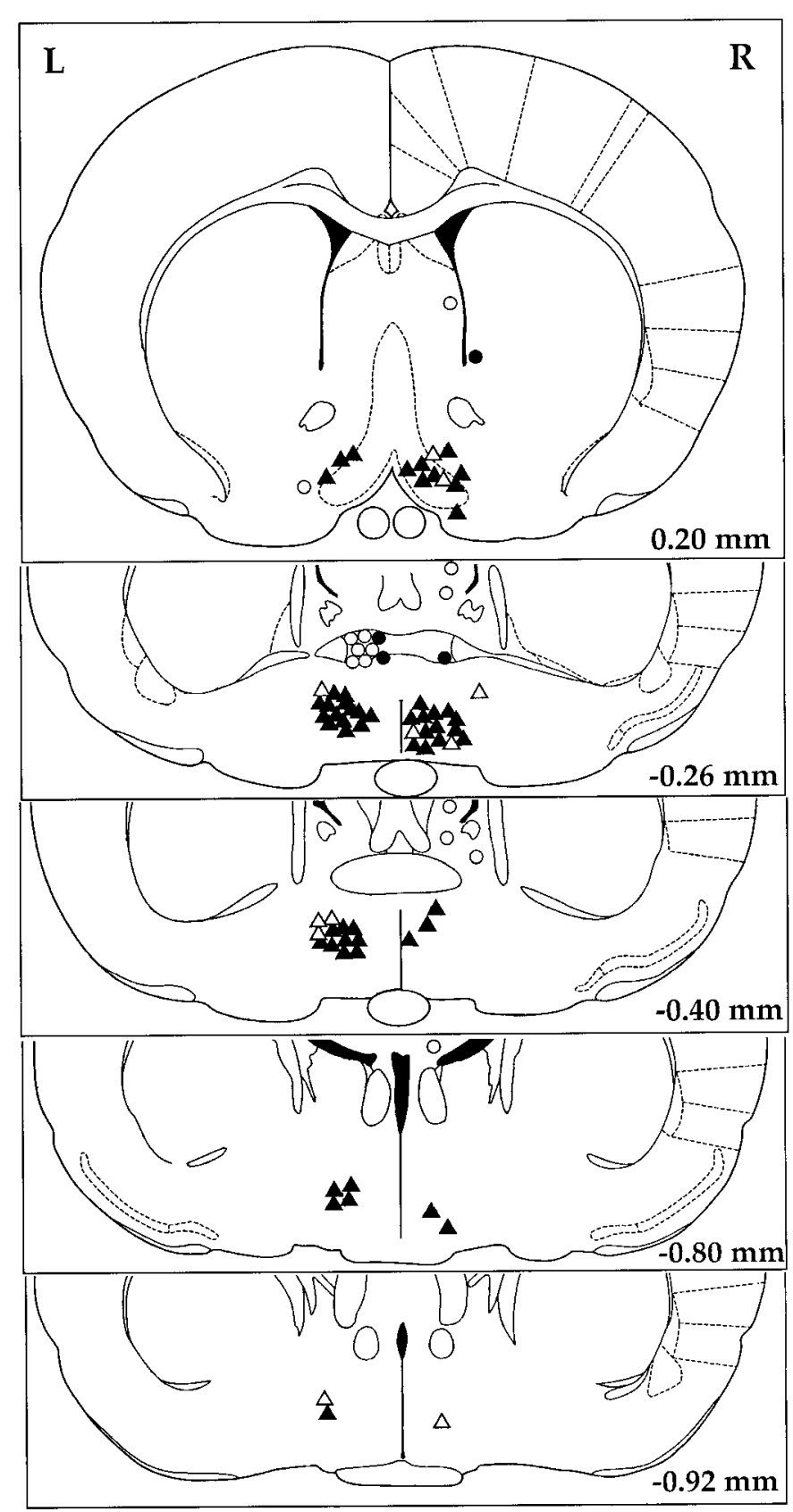

Figure 5. Microinjection sites of GHRH and the GHRH antagonist illustrated on the schematic drawings from the rat brain atlas (Paxinos and Watson, 1986). Closed symbols denote active and open symbols represent inactive injection sites. The data obtained after injections into the sites marked by triangles (closed or open) were used in the statistical analyses. Injection sites denoted by circles (closed or open) were considered misplaced, and the data collected in these experiments were excluded from the statistics. For illustration purposes, all injection sites of the GHRH are depicted on the right side $(R)$, and all injection sites of the GHRH antagonist are depicted on the left side $(L)$. Values in the bottom right corner are distances from the bregma.

1991). The duration of the inhibitory effect after intrapreoptic injection was also more prolonged than was the suppression elicited by intracerebroventricular injection. The differences in the duration of action indicate that the intrapreoptic injection is more potent than is the intraventricular administration. Finally, the intrapreoptic injection of the GHRH antagonist attenuated 
the sleep deprivation-induced enhancements in NREMS. This finding confirms the previous report (Obál et al., 1992) showing that immunoneutralization of GHRH blocks recovery NREMS after sleep deprivation.

Although the NREMS responses to intrapreoptic GHRH and antagonist are similar to those found after intracerebroventricular administration of these peptides, there is an obvious difference between the two routes of injection in the effects on REMS. Intrapreoptic injection of GHRH or the GHRH antagonist had little influence on REMS. In fact, administration of the high dose of the GHRH antagonist was the only manipulation that slightly reduced REMS. This dose of the antagonist, however, elicited significant rises in $\mathrm{T}_{\mathrm{br}}$, and the decreases in REMS might result from fever. In contrast, intracerebroventricular injection of GHRH stimulates REMS in rabbits, although the increases in REMS occur only after a $1 \mathrm{hr}$ latency, at a time when enhancements of NREMS already decline (Obál et al., 1988). Increases in REMS are also observed in response to GHRH administered into the cerebral ventricles in rats, but the effect is less consistent than is that in rabbits and does not display dose-response relationships (Obál et al., 1988). That the mediation of the NREMSand REMS-promoting activities of GHRH is different is clearly shown by experiments in hypophysectomized rats. GHRHinduced increases in NREMS survive the removal of the pituitary gland, whereas GHRH fails to stimulate REMS in hypophysectomized rats (Obál et al., 1996). This finding indicates that stimulation of REMS by GHRH requires the presence of pituitary hormones, most likely $\mathrm{GH}$, and might be mediated by $\mathrm{GH}$. Acute systemic GH administration in fact increases REMS in rats (Drucker-Colin et al., 1975), cats (Stern et al., 1975), and humans (Mendelson et al., 1980). The difference in the effects in REMS between intrapreoptic and intracerebroventricular (or systemic) injections of GHRH might be related to the differences in the access of GHRH to the pituitary. GHRH leaks into the pituitary portal vessels and stimulates $\mathrm{GH}$ secretion after intracerebroventricular injection (Wehrenberg and Ehlers, 1986). It is unlikely that GHRH reaches the pituitary when administered into the preoptic area.

Stimulation and inhibition of NREMS by intrapreoptic injections of GHRH and the GHRH antagonist, respectively, provide support for the hypothesis that the sleep-promoting activity of GHRH is a neurotransmitter- and/or neuromodulator-like function of GHRHergic neurons projecting to the basal forebrain. If we count only the number of the effective injection sites after the two highest doses of both GHRH and the GHRH antagonist, a total of 78 injection sites were tested in our experiments. The majority of these sites (68) were inside of the preoptic region and the diagonal band of Broca, and only 18 were clearly misplaced. The lack of positive sleep responses to the majority of the injections above the preoptic region suggests that the sleep effects of GHRH or the antagonist are not caused by a backflow into the ventricular system. That a few injections of effective doses of GHRH or the antagonist failed to enhance or suppress sleep can be attributed to factors that could not be controlled. For example, a small, unnoticed air bubble in the injection cannula results in the failure of the delivery of a fluid volume as small as $0.3-0.5 \mu \mathrm{l}$. Sometimes injections outside of the preoptic area elicited normal sleep responses. The distance of misplacement of these injection sites, however, was not large enough to exclude the possibility of diffusion of the peptides into the preoptic area or, in one case, into the lateral ventricle. Hence, the conclusion of the current experiments is that GHRHergic stimulation in the preoptic re- gion, particularly in the medial preoptic area, promotes NREMS, but it remains to be determined whether other structures in the basal forebrain are also responsive to GHRH.

The importance of the anterior hypothalamus and preoptic region in sleep regulation was first indicated by Von Economo's (1930) observation that patients with viral infection-associated damage in this area suffered from insomnia. Hess (1944) reported signs of sleep in response to electrical stimulation in the anterior hypothalamus and preoptic region, whereas transection at the level of the preoptic region resulted in severe sleep loss in the experiments by Nauta (1946). Subsequent papers reporting results with electrical stimulation in acute immobilized cats (Sterman and Clemente, 1962a; Benedek et al., 1979) and chronically implanted animals (Sterman and Clemente, 1962b) confirmed the sleep-promoting activity of this area. Furthermore, lesions of the preoptic region produce insomnia (McGinty and Sterman, 1968; Asala et al., 1990; Szymusiak et al., 1991). The preoptic region mediates increases in sleep in response to thermal stimuli (Roberts and Robinson, 1969). This area is also responsive to a number of sleep-promoting substances. Local administration of adenosine agonists (Ticho and Radulovacki, 1991), prostaglandin D2 (Hayaishi, 1988), progesterone (Heuser et al., 1967), $\alpha$-adrenergic agonists (Kumar et al., 1984), serotonin (Denoyer et al., 1988), and benzodiazepines (Mendelson et al., 1989) enhances sleep, and the preoptic area is also involved in the mediation of the sleep effects of uridine (Kimura-Takeuchi and Inoue, 1993). In contrast, intrapreoptic injection of prostaglandin E2 (Hayaishi, 1988) and the GABAergic agonist muscimol (Lin et al., 1989) reduces sleep. A large increase in the expression of the early gene c-fos is observed in the preoptic region after both spontaneous and forced wakefulness, and intrapreoptic injection of c-fos antisense oligonucleotides suppresses sleep (Pompeiano et al., 1995). The preoptic area is also a target for the projections of GHRHergic neurons (Sawchenko et al., 1985). These neurons are different from the hypophyseotropic GHRHergic neurons that are located in the arcuate nucleus. The GHRHergic neurons that innervate the basal forebrain reside outside of the arcuate nucleus. Experiments with in situ hybridization show that the GHRHergic neurons, which are responsive to sleep deprivation and exhibit diurnal rhythms, are in fact extra-arcuate neurons around the periventromedial nucleus and in the parvicellular portion of the paraventricular nucleus (Toppila et al., 1997). The nature of the preoptic neurons that receive GHRHergic inputs is not known. Nevertheless, GABAergic projections are a likely candidate to mediate the sleep-promoting activity of the preoptic region (Gritti et al., 1994).

In addition to the proposed fundamental role in sleep regulation, the preoptic area has been implicated in the modulation of a number of endocrine, autonomic, and behavioral functions. Thermoregulation and the mediation of fever are among these functions. A puncture in the preoptic region is reported to elicit rapid febrile responses attributed to prostaglandin release (Rudy et al., 1977). Tissue injuries activate various cytokines, which stimulate the production of prostaglandins; e.g., interleukin-1 is released in response to microinjuries of the brain tissue (Woodroofe et al., 1991). Both cytokines and prostaglandins influence sleep; interleukin-1, tumor necrosis factor (Krueger et al., 1984), and prostaglandin D2 increase whereas prostaglandin E2 decreases NREMS (Hayaishi, 1988). It was important for us to distinguish clearly the sleep effects elicited by GHRH or the GHRH antagonist from the alterations associated with the microinjection procedure per se. The changes in sleep and $\mathrm{T}_{\mathrm{br}}$ were, 
therefore, determined after injection of physiological saline, and the order of physiological saline and peptide administrations was randomly varied in the experiments. The results confirmed that the injection procedure causes prompt fever. Sleep, particularly NREMS, was also enhanced for $\sim 3 \mathrm{hr}$ after injection of physiological saline; the effects of GHRH and the antagonist occurred superimposed to the sleep alterations elicited by the injection procedure per se.

In conclusion, the current results confirm previous reports on the role of GHRH in sleep regulation and indicate that the preoptic region is involved in the mediation of the NREMSpromoting activity of GHRH.

\section{REFERENCES}

Asala SA, Okano Y, Honda K, Inoue S (1990) Effects of medial preoptic area lesions on sleep and wakefulness in unrestrained rats. Neurosci Lett 114:300-304.

Benedek G, Obál Jr F, Szekeres L, Obál F (1979) Two separate synchronizing mechanisms in the basal forebrain: study of the synchronizing effects of the rostral hypothalamus preoptic region and olfactory tubercle. Arch Ital Biol 117:164-185.

Borbély AA (1982) A two process model of sleep regulation. Hum Neurobiol 1:195-204.

Bredow S, Taishi P, Obál Jr F, Guha-Thakurta N, Krueger JM (1996) Hypothalamic growth hormone-releasing hormone mRNA varies across the day in rats. NeuroReport 7:2501-2505.

Daikoku S, Kawano H, Noguchi M, Nakanishi J, Tokuzen M, Chihara K, Nagatsu I (1986) GRF neurons in the rat hypothalamus. Brain Res 399:250-261.

Denoyer M, Sallanon M, Kitahama K, Aubert C, Jouvet M (1989) Reversibility of para-chlorophenylalanine-induced insomnia by intrahypothalamic microinjection of L-5-hydroxytryptophan. Neuroscience 28:83-94.

Drucker-Colin RR, Spanis CW, Hunyadi J, Sassin JF, McGaugh JL (1975) Growth hormone effects on sleep and wakefulness in the rat. Neuroendocrinology 18:1-8.

Ehlers CL, Reed TK, Henriksen SJ (1986) Effects of corticotropinreleasing factor and growth hormone-releasing factor on sleep and activity in rats. Neuroendocrinology 42:467-474.

Feinberg I (1989) Effects of maturation and aging on slow-wave sleep in man: implications for neurobiology. In: Slow wave sleep: physiological, pathological and functional aspects (Wauquier A, Dugovic C, Radulovacki M, eds), pp 31-47. New York: Raven.

Gardi J, Obál Jr F, Zhang J, Fang J, Krueger JM (1998) Diurnal and sleep deprivation-induced changes in the GHRH contents of the rat hypothalamus. J Sleep Res 7[Suppl 3]:97.

Gritti I, Mainville L, Jones BE (1994) Projections of GABAergic and cholinergic basal forebrain and GABAergic preoptic-anterior hypothalamic neurons to the posterior lateral hypothalamus of the rat. J Comp Neurol 339:251-268.

Hayaishi O (1988) Sleep-wake regulation by prostaglandins D2 and E2. J Biol Chem 263:14593-14596.

Hess WR (1944) Hypothalmische adynamie. Helv Physiol Pharmacol Acta 2:137-147.

Heuser G, Ling GM, Kluver M (1967) Sleep induction by progesterone in the pre-optic area in cats. Electroencephalogr Clin Neurophysiol 22:122-127.

Johnson AK, Epstein AN (1975) The cerebral ventricles as the avenue for the dipsogenic action of intracranial angiotensin. Brain Res $86: 399-418$.

Kerkhofs M, Van Cauter E, Van Onderbergen A, Caufirez A, Thorner MO, Copinschi G (1993) Growth hormone-releasing hormone $(\mathrm{GHRH})$ has sleep promoting effects in man. Am J Physiol 264:E594-E598.

Kimura-Takeuchi M, Inoue S (1993) Lateral preoptic lesions void slowwave sleep enhanced by uridine but not by muramyl dipeptide in rats. Neurosci Lett 157:17-20.

Krueger JM, Obál Jr F (1993) Growth hormone-releasing hormone and interleukin1 in sleep regulation. FASEB J 7:645-652.

Krueger JM, Walter J, Dinarello CA, Wolff SM, Chedid L (1984) Sleeppromoting effects of endogenous pyrogen (interleukin-1). Am J Physiol 246:R994-R999.
Kumar VM, Datta S, Chhina GS, Gandhi N, Singh B (1984) Sleepawake responses elicited from medial preoptic area on application of norepinephrine and phenoxybenzamine in free moving rats. Brain Res 322:322-325.

Lin JS, Sakai K, Vanni-Mercier G, Jouvet M (1989) A critical role of the posterior hypothalamus in the mechanisms of wakefulness determined by microinjection of muscimol in freely moving cats. Brain Res 479:225-240.

Marshall L, Molle M, Boschen G, Steiger A, Fehm HL, Born J (1996) Greater efficacy of episodic than continuous growth hormone-releasing hormone (GHRH) administration in promoting slow-wave sleep (SWS). J Clin Endocrinol Metab 81:1009-1013.

McGinty DJ, Sterman MB (1968) Sleep suppression after basal forebrain lesions in the cat. Science 160:1253-1255.

Mendelson WB, Slater S, Gold P, Gillin JC (1980) The effect of growth hormone administration on human sleep: a dose-response study. Biol Psychiatry 15:613-618.

Mendelson WB, Martin JV, Perlis M, Wagner R (1989) Enhancement of sleep by microinjection of triazolam into the medial preoptic area. Neuropsychopharmacology 2:61-66.

Merchenthaler I, Thomas CR, Akimura A (1984) Immunocytochemical localization of growth hormone releasing factor (GHRF)-containing structures in the rat brain using anti-rat GHRF serum. Peptides 5:1071-1076.

Nauta WJH (1946) Hypothalamic regulation of sleep in rats. An experimental study. J Neurophysiol 9:285-316.

Nistico G, DeSarro GB, Bagetta G, Müller EE (1987) Behavioral and electrocortical spectrum power effects of growth hormone releasing factor in rats. Neuropharmacology 26:75-78.

Obál Jr F, Alföldi P, Cady AB, Johannsen L, Sáry G, Krueger JM (1988) Growth hormone releasing factor enhances sleep in rats and rabbits. Am J Physiol 255:R310-R316.

Obál Jr F, Payne L, Kapás L, Opp M, Krueger JM (1991) Inhibition of growth hormone-releasing hormone suppresses both sleep and growth hormone secretion in the rat. Brain Res 557:149-153.

Obál Jr F, Payne L, Opp M, Alföldi P, Kapás L, Krueger JM (1992) Growth hormone-releasing hormone antibodies suppress sleep and prevent enhancement of sleep after sleep deprivation. Am J Physiol 263:R1078-R1085.

Obál Jr F, Floyd R, Kapás L, Bodosi B, Krueger JM (1996) Effects of systemic GHRH on sleep in intact and hypophysectomized rats. Am J Physiol 270:E230-E237.

Paxinos G, Watson C (1986) The rat brain in stereotaxic coordinates, 2nd Edition. San Diego: Academic.

Pompeiano M, Cirelli C, Arrighi P, Tononi G (1995) c-Fos expression during wakefulness and sleep. Neurophysiol Clin 250:329-341.

Roberts WW, Robinson TCL (1969) Relaxation and sleep induced by warming of the preoptic region and anterior hypothalamus in cats. Exp Neurol 25:282-294.

Rudy TA, Williams JW, Yaksh TL (1977) Antagonism by indomethacin of neurogenic hyperthermia produced by unilateral puncture of the anterior hypothalamic/preoptic region. J Physiol (Lond) 272:721-736.

Sawchenko PE, Swanson LW, Rivier J, Vale WW (1985) The distribution of growth hormone-releasing factor (GRF) immunoreactivity in the central nervous system of the rat: an immunohistochemical study using antisera directed against rat hypothalamic GRF. J Comp Neurol 237:100-115.

Steiger A, Guldner J, Hemmeter U, Rothe B, Wiedemann K, Holsboer F (1992) Effects of growth hormone-releasing hormone and somatostatin on sleep EEG and nocturnal hormone secretion in male controls. Neuroendocrinology 56:566-573.

Sterman MB, Clemente CD (1962a) Forebrain inhibitory mechanisms: cortical synchronization induced by basal forebrain stimulation. Exp Neurol 6:91-102.

Sterman MB, Clemente CD (1962b) Forebrain inhibitory mechanisms: sleep patterns induced by basal forebrain stimulation in the behaving cat. Exp Neurol 6:103-117.

Stern WC, Jalowiec JE, Shabshelowitz H, Morgane P (1975) Effects of growth hormone on sleep-waking patterns in cats. Horm Behav 6:189-196.

Szymusiak R (1995) Magnocellular nuclei of the basal forebrain: substrates of sleep and arousal regulation. Sleep 18:478-500.

Szymusiak R, Danowski J, McGinty D (1991) Exposure to heat restores sleep in cats with preoptic/anterior hypothalamic cell loss. Brain Res 541:134-138. 
Takahashi T, Okimura Y, Yoshimura K, Shigeyoshi Y, Kaji H, Abe H, Chihara K (1995) Regional distribution of growth hormone-releasing hormone (GHRH) receptor mRNA in the rat brain. Endocrinology 136:4721-4724.

Ticho SR, Radulovacki M (1991) Role of adenosine in sleep and temperature regulation in the preoptic area of rats. Pharmacol Biochem Behav 40:33-40.

Toppila J, Alanko L, Asikainen M, Tobler I, Stenberg D, PorkkaHeiskanen T (1997) Sleep deprivation increases somatostatin and growth hormone-releasing hormone messenger RNA in the rat hypothalamus. J Sleep Res 6:171-178.

Von Economo C (1930) Sleep as a problem of localization. J Nerv Ment Dis 71:249-259.
Wehrenberg WB, Ehlers CL (1986) Effects of growth hormone-releasing factor in the brain. Science 232:1271-1272.

Woodroofe MN, Sarna GS, Wadhwa M, Hayes GM, Loughlin AJ, Tinker A, Cuzner ML (1991) Detection of interleukin-1 and interleukin-6 in adult rat brain, following mechanical injury, by in vivo microdialysis: evidence of a role for microglia in cytokine production. J Neuroimmunol 33:227-236.

Zhang J, Obál Jr F, Fang J, Collins BJ, Krueger JM (1996) Non-rapid eye movement sleep is suppressed in transgenic mice with a deficiency in the somatotropic system. Neurosci Lett 220:97-100.

Zhang J, Chen Z, Taishi P, Obál Jr F, Fang J, Krueger JM (1998) Sleep deprivation increases rat hypothalamic growth hormone-releasing hormone mRNA. Am J Physiol 275:R1755-R1761. 